\title{
MODELING GRINDING PROCESSES AS MICRO-MACHINING OPERATION
}

\author{
A. S. Olayinka ${ }^{1, *}$ and A. C. Igboanugo ${ }^{2}$

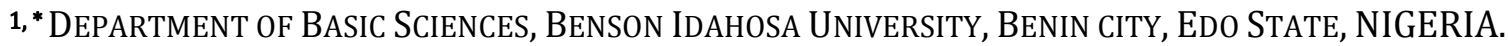 \\ 2 Department of Production Engineering, University of Benin, Benin-City, Edo State, NiGERIA. \\ Email addresses:1 solayinka@biu.edu.ng, 22dracigboanugo@yahoo.com
}

\begin{abstract}
Quest for precision components and parts in manufacturing industries has led to an increase in the need for effective and efficient finishing operations that can satisfy this increasing demand. Grinding process can meet these critical needs for accurate and economic means of finishing parts, and generate the required surface topography. Modeling of grinding is necessary to understand the effects of process conditions, grinding wheel properties and workpiece material dynamics thus allowing for process planning, optimization, and control. In spite of the enormous potentials offered by grinding, it still remains one of the most difficult and least-understood concept in manufacturing processes due to lack of adequate models to explain the phenomenon. A computational based model for surface grinding process as a micro-machined operation has been developed. In this model, grinding forces are made up of chip formation force and sliding force. Mathematical expressions for Modeling tangential grinding force and normal grinding force were obtained. The model was used to calculate the tangential and normal grinding force at different values of wheel velocity, grinding depth and workpiece feed velocity. The results obtained from the model showed that the grinding forces increased with increase in grinding depth and workpiece feed velocity but with decrease in grinding wheel velocity. The grinding wheel diameter does not have any significant effect in the Grinding forces. The results obtained with this model were validated by comparing it with available experimental results and the agreement between the model's results and experimental results was reasonable.
\end{abstract}

Keywords: grinding processes, modeling, micro-machining operation, grinding force

\section{INTRODUCTION}

Grinding is a very important manufacturing process, mainly where tight dimensional accuracy and low workpiece surface roughness are demanded. The grinding process is usually the last machining operation of a surface and therefore has a high aggregated cost. Despite its low material removal rate, the grinding process is the most common way to obtain smooth surfaces. In order to improve the process productivity and product quality, a number of researches have sought to promote different techniques and sensors for monitoring the grinding process $[1,2,5,6,7]$.Grinding is one of the most employed finish processes for the manufacturing of precision workpieces, even being a low technology machining process, when compared to conventional machining processes like drilling, milling etc. Its performance depends upon the operator's ability and sensibility and the grinding wheel machining conditions [2].Grinding is a material removal and surface generation process used to shape and finish components made of metals and other materials. The precision and surface finish obtained through grinding can be up to ten times better than with either turning or milling. Grinding is widely used for final machining of components requiring smooth surfaces and precise tolerances. Extensive research conducted during the past 40 years has provided a relatively clear understanding of the many diverse aspects of the grinding process $[1,2,3]$.

Grinding is typically utilized as a finishing process, therefore any mistake that damage the workpiece are costly and almost certainly irreversible [4]. Grinding is an extensively used process to finish machined parts that require high surface quality and tight tolerances. Grinding is an abrasive process where the tool, composed by small abrasive grits bonded together, presents a very complex interaction with the workpiece, making the process difficult to predict. More than fifty years of research have been focused on 
the interaction between the processes, machine and workpiece parameters related to the output variables such us surface roughness and residual stresses. The lack of a complete understanding of the process and the low practicality of these analytical equations has forced the use of purely empirical equation for the process optimization. These empirical equations are simple in structure but their reliability depends on the sensor technology and on-line parameter estimation techniques to count for the no modeled process variations.

Grinding may be classified as non-precision or precision according to purpose and procedure. Nonprecision grinding includes snagging and offhand grinding. Both are done primarily to remove stock that cannot be taken off as conveniently by other methods. The workpiece is pressed hard against the wheel or vice versa. The accuracy and surface finish are of secondary importance. Precision grinding on the other hand is concerned with producing good surface finishes and accurate dimensions. There are many forms of precision grinding, but the three major industrial precision grinding processes are cylindrical, center less and surface grindings.

Several model shave been proposed and used to study grinding processes over the years. Walsh et al. developed a model for crankshaft pin grinding to predict the forces generated during grinding [8], a stochastic grinding force model as a function of the grinding conditions and grit distributions has also been studied [9]. In 1999, Gavrilov et al. developed a model to simulate grinding in a shaker ball mill so as to understand the mechanisms of alloying in order to design better equipment for producing mechanically alloyed material [10], the results obtained from their model compared favourably with experimental results of Shaw et al. [11]. Probabilistic model of the grinding process was developed based on well-founded assumptions by Stepien [12] to consider the random arrangement of the grain vertices at the wheel active surface. Ilio et al. [13] proposed some relationship for Modeling force components, cutting energy and work piece surface roughness in grinding of metal matrix composites. Modeling of dynamic micro-milling cutting forces was presented [14] with the effect of plowing, elastic recovery, run-out and dynamics on micromilling forces examined.

The continuous demand for hard and tough materials that can withstand varying stress conditions to ensure prolonged service life of components and parts and the needs for precision in processing these materials in manufacturing industries is the motivation behind this research. The need to process these materials economically so as to meet stringent product quality requirements has become a real challenge for researchers and practitioners in manufacturing industries. Grinding process can meet these critical needs for accurate and economic means of finishing parts, and generate the required surface topography.

In this work, we develop a computational model using FORTRAN 95 for grinding process to simulate the tangential and normal grinding forces. With the model we studied the effects of the tangential and normal grinding forces with grinding wheel velocity, grinding depth, grinding wheel diameter and workpiece velocity.

\section{MATHEMATICAL FORMULATION}

Grinding forces are generally divided into cutting deformation force and sliding force.

$$
\begin{aligned}
\text { GrindingForce } & =F_{\text {CuttingDeformation }} \\
& +F_{\text {Sliding }}
\end{aligned}
$$

Where $F_{\text {CuttingDeformation }}$ is Cutting deformation force and $F_{\text {Sliding }}$ is the Sliding force, however, Cutting deformation force is divided into chip formation force and plowing force but plowing force is negligible $[15,16]$ therefore equation (1) can be re- written as :

$$
\text { GrindingForce }=F_{\text {Chip }}+F_{\text {Sliding }}
$$

Grinding forces can be separated into Normal Grinding Force $\left(F_{n}\right)$ and Tangential Grinding Force $\left(F_{t}\right)$ as given below.

$$
\left\{\begin{array}{l}
F_{n}=F_{n, \text { chip }}+F_{n, \text { sliding }} \\
F_{t}=F_{t, \text { chip }}+F_{t, \text { sliding }}
\end{array}\right.
$$

where $F_{n, c h i p}$ is the normal chip formation force, $F_{t, \text { chip }}$ is the tangential chip formation force, $F_{n, \text { sliding }}$ is the normal sliding force, and $F_{t, \text { sliding }}$ is the tangential sliding force.

Specific chip formation energy $u_{c h}$ can be written as

$u_{\text {chip }}=\frac{\mathrm{F}_{t, \text { chip }} V_{s}}{V_{w} a_{p} b}$

where, $V_{s}$ is the grinding wheel velocity, $V_{w}$ is the work piece feed velocity, $a_{p}$ is the grinding depth, and $b$ is the grinding width.

Specific chip formation energy $u_{\text {chip }}$ can be separated into two parts: static specific chip formation energy $u_{s}$ and dynamic specific chip formation energy $u_{d}$.

$u_{\text {chip }}=u_{s}+u_{d}$

where static specific chip formation energy $u_{s}$ is a constant which is determined by experiment according 
to element material and grinding wheel material. Dynamic specific chip formation energy $u_{d}$ is determined by element material, grinding wheel material and grinding processing parameters. $u_{d}$ is given by [16] as:

$u_{d}=K_{2} \ln \frac{k(C r)^{0.5} d_{e}^{0.25} V_{s}^{1.5}}{\dot{\gamma}_{o} a_{p}^{0.25} V_{w}^{0.5}}$

Where $k$ is a constant. Here $C$ is the number of effective abrasive blades in unit area of grinding wheel, $r$ is the ratio of chip thickness, and $d_{e}$ is the equivalent diameter of wheel. $\dot{\gamma}$ is the strain rate of grinding progress, $K_{2}$ and $\dot{\gamma}_{o}$ are constants determined by experiment,

Substituting equation (6) into equation (5)

$u_{c h}=u_{s}+K_{2} \ln \left(\frac{k(c r)^{0.5} d_{e}^{0.25} V_{s}^{1.5}}{\dot{\gamma}_{o} a_{p}^{0.25} V_{w}^{0.5}}\right)$

If we consider,

$K_{1}=u_{s}+K_{2} \ln \left(\frac{k(C r)^{0.5} d_{e}^{0.25}}{\dot{\gamma}_{o}}\right)$

Then equation (7) becomes

$u_{c h}=K_{1}+K_{2} \ln \left(\frac{V_{s}^{1.5}}{a_{p}^{0.25} V_{w}^{0.5}}\right)$

By using equation (4) the tangential chip formation force in grinding machining can be written as

$$
\begin{gathered}
F_{t . c h}=u_{c h} \frac{V_{w} a_{p}}{V_{s}} b=\left(K_{1}+K_{2} \ln \left(\frac{V_{s}^{1.5}}{a_{p}^{0.25} V_{w}^{0.5}}\right)\right) \frac{V_{w} a_{p}}{V_{s}} b \\
=K_{1} \frac{V_{w} a_{p}}{V_{s}} b \\
+K_{2} \frac{b V_{w} a_{p}}{V_{s}} \ln \frac{V_{s}^{1.5}}{a_{p}^{0.25} V_{w}^{0.5}}
\end{gathered}
$$

Here $K_{1}\left(\frac{V_{w} a_{p}}{V_{s}}\right) b$ is the static tangential chip formation force and $K_{2}\left(\frac{b V_{w} a_{p}}{V_{s}}\right) \ln \left(\frac{V_{s}^{1.5}}{a_{p}^{0.25} V_{w}^{0.5}}\right)$ is the dynamic tangential chip formation force. Setting $\varphi_{1}$ and $\varphi_{2}$ as the ratio of static normal chip formation force to static tangential chip formation force and the ratio of dynamic normal chip formation force to dynamic tangential chip formation force, respectively, and normal chip formation force is

$$
\begin{aligned}
F_{n . c h}=\varphi_{1} K_{1}\left(\frac{V_{w} a_{p}}{V_{s}}\right) b \\
\\
\quad+\varphi_{2} K_{2}\left(\frac{b V_{w} a_{p}}{V_{s}}\right) \ln \left(\frac{V_{s}^{1.5}}{a_{p}^{0.25} V_{w}^{0.5}}\right)
\end{aligned}
$$

Considering $K_{3}=\varphi_{1} K_{1}$ and $K_{4}=\varphi_{2} K_{2}$, equation 11 becomes

$$
F_{n . c h}=\left(K_{3}+K_{4} \ln \left(\frac{V_{s}^{1.5}}{a_{p}^{0.25} V_{w}^{0.5}}\right)\right) \frac{V_{w} a_{p}}{V_{s}} b
$$

In the geometric dynamics analysis of grinding grains, using parabola function to approximate cutting path, the deviation between the grinding wheel radius and the radius of curvature of cutting path is:

$\Delta= \pm \frac{4 V_{w}}{d_{e} V_{s}}$

In this equation, positive sign is used for up grinding and negative sign is used for down grinding.

Experimental data [17] indicates that the average contact press $\bar{p}$ between workpiece and abrasive grains wore plane approximately linearly increases as the deviation $\Delta$ of radius of curvature increases, this relationship can be given by equation [16]

$\bar{p}=p_{o} \Delta=\frac{4 p_{o} V_{w}}{d_{e} V_{s}}$

Here $p_{o}$ is a constant and can be determined by experiment. From this equation, the average contact press $\bar{p}$ between workpiece and abrasive grains wore plane varies with processing parameters of grinding. Therefore, there is likely to be elastic contact, elastoplastic contact or plastic contact. So the frictional coefficient $\mu$ varies with the average contact press $\bar{p}$. According to the friction binomial theorem, the frictional coefficient is:

$\mu=\frac{\alpha A_{0}}{W}+\beta=\frac{\alpha}{\bar{p}}+\zeta$

Here $\mathrm{W}$ is the normal load, $A_{0}$ is the contact area, and $\alpha$ and $\zeta$ are coefficients which are determined by physical and mechanical properties of contact interface.

Tangential sliding force and normal sliding force [16, 18] are as follows

$$
\begin{aligned}
& F_{t, s l}=\mu \bar{p} b A\left(d_{e} a_{p}\right)^{1 / 2} \\
& F_{n, s l}=\bar{p} b A\left(d_{e} a_{p}\right)^{1 / 2}
\end{aligned}
$$

where $A$ is the area ratio of grinding wheel's wear surface. Substituting equation (15) and (16) into equation (16) and (17) yields:

$$
\begin{gathered}
F_{t, s l}=b A\left(\alpha+\frac{4 \beta p_{o} V_{w}}{d_{e} V_{s}}\right)\left(d_{e} a_{p}\right)^{1 / 2} \\
F_{n, s l}=\frac{4 b A p_{o} V_{w}}{V_{s}}\left(\frac{a_{p}}{d_{e}}\right)^{1 / 2}
\end{gathered}
$$

\subsection{Modeling Expression for Grinding Force}

Substituting equations (10), (12), (18), and (19) into equation (1), yields an equation for grinding force for surface grinding as follow: 
$\left\{\begin{array}{l}F_{t}=\left(K_{1}+K_{2} \ln \left(\frac{V_{s}^{1.5}}{a_{p}^{0.25} V_{w}^{0.5}}\right)\right) \frac{V_{w} a_{p}}{V_{s}} b+b A\left(\alpha+\frac{4 \beta p_{o} V_{w}}{d_{e} V_{s}}\right)\left(d_{e} a_{p}\right)^{1 / 2} \\ F_{n}=\left(K_{3}+K_{4} \ln \left(\frac{V_{s}^{1.5}}{a_{p}^{0.25} V_{w}^{0.5}}\right)\right) \frac{V_{w} a_{p}}{V_{s}} b+\frac{4 b A p_{o} V_{w}}{V_{s}}\left(\frac{a_{p}}{d_{e}}\right)^{1 / 2}\end{array}\right.$

Several coefficients of equation (20) depends on experimental data, its deduction is based on Malkin's grinding theory, classical mental material cutting deformation theory and the associated disciplinarian about grinding processing parameters and cutting dynamic mechanical properties of metal material, considering the influence of grinding processing parameters to the friction coefficient between workpiece and grinding wheel. From equation (20), the calculation formulas of the tangential grinding force per unit width $F_{t}^{\prime}$ and the normal grinding force per unit width $F_{n}^{\prime}$ can be represented as

$\left\{\begin{array}{l}F_{t}^{\prime}=\left(K_{1}+K_{2} \ln \left(\frac{V_{s}^{1.5}}{a_{p}^{0.25} V_{w}^{0.5}}\right)\right) \frac{V_{w} a_{p}}{V_{s}}+A\left(\alpha+\frac{4 \beta p_{o} V_{w}}{d_{e} V_{s}}\right)\left(d_{e} a_{p}\right)^{1 / 2} \\ F_{n}^{\prime}=\left(K_{3}+K_{4} \ln \left(\frac{V_{s}^{1.5}}{a_{p}^{0.25} V_{w}^{0.5}}\right)\right) \frac{V_{w} a_{p}}{V_{s}}+\frac{4 A p_{o} V_{w}}{V_{s}}\left(\frac{a_{p}}{d_{e}}\right)^{1 / 2}\end{array}\right.$

If $\alpha_{0}=A \alpha, \beta_{0}=4 \beta A p_{o}$ and $\varepsilon_{0}=4 A p_{o}$, then, equation (21) becomes

$\left\{\begin{array}{l}F_{t}^{\prime}=\left(K_{1}+K_{2} \ln \left(\frac{V_{s}^{1.5}}{a_{p}^{0.25} V_{w}^{0.5}}\right)\right) \frac{V_{w} a_{p}}{V_{s}}+\left(\alpha_{o}+\beta_{o} \frac{V_{w}}{d_{e} V_{s}}\right)\left(d_{e} a_{p}\right)^{1 / 2} \\ F_{n}^{\prime}=\left(K_{3}+K_{4} \ln \left(\frac{V_{s}^{1.5}}{a_{p}^{0.25} V_{w}^{0.5}}\right)\right) \frac{V_{w} a_{p}}{V_{s}}+\frac{\varepsilon_{o} V_{w}}{V_{s}}\left(\frac{a_{p}}{d_{e}}\right)^{1 / 2}\end{array}\right.$

There are seven unknown parameters: $K_{1}, K_{2}, K_{3}, K_{4}, \alpha_{o}, \beta_{o}, \varepsilon_{0}$ in equation (22) which is taken from the experimental data [16]. Substituting these constants into equation (22) and solving linear equations, the modeling expression for grinding force is obtained as

$$
\left\{\begin{array}{l}
F_{t}^{\prime}=\left(237,433-30,990 \ln \left(\frac{V_{s}^{1.5}}{a_{p}^{0.25} V_{w}^{0.5}}\right)\right) \frac{V_{w} a_{p}}{V_{s}}+\left(0.8367+6066 \frac{V_{w}}{d_{e} V_{s}}\right)\left(d_{e} a_{p}\right)^{1 / 2} \\
F_{n}^{\prime}=\left(220,979+21,766 \ln \left(\frac{V_{s}^{1.5}}{a_{p}^{0.25} V_{w}^{0.5}}\right)\right) \frac{V_{w} a_{p}}{V_{s}}+24,175 \frac{V_{w}}{V_{s}}\left(\frac{a_{p}}{d_{e}}\right)^{1 / 2}
\end{array}\right.
$$

\section{RESULTS AND DISCUSSION}

\subsection{Tangential Grinding Force}

The variation of Tangential Grinding Force per unit width with the Grinding depth at work piece velocity, $\mathrm{V}_{\mathrm{w}}=0.15 \mathrm{~m} / \mathrm{s}$ is shown in Fig. 1 forour model as compared with the experimental data of Yang et al. [19]. The figure reveals that the Tangential Grinding Force increases with increase in the grinding depth for both the model and experimental data. Fig. 2 shows the variation of Tangential Grinding Force per unit width per unit width with the Grinding depth for different wheel diameters $(125 \mathrm{~mm}, 200 \mathrm{~mm}$ and $250 \mathrm{~mm}$ ) at work piece velocity, $\mathrm{V}_{\mathrm{w}}=0.15 \mathrm{~m} / \mathrm{s}$. Fig. 2 reveals that there is no significant variation in the Tangential Grinding Force when the diameter of the wheel is varied. Fig. 3 shows the variation of
Tangential Grinding Force per unit width with the Grinding depth at work piece velocity, $\mathrm{V}_{\mathrm{w}}=0.3 \mathrm{~m} / \mathrm{s}$ for the model and experimental data. Fig. 3 reveals that the Tangential grinding force increases with increase in the grinding depth for both the model and experimental data. Comparing Fig. 1 with Fig. 3shows that Tangential Grinding Force increase with increase in work piece velocity. From Fig. 1, the Tangential Grinding Force obtained at $0.006 \mathrm{~mm}$ Grinding depth is $1.76236 \mathrm{~N} / \mathrm{mm}$ while in Fig. 3 the equivalent Tangential Grinding Force obtained at $0.006 \mathrm{~mm}$ Grinding depth is $3.60564 \mathrm{~N} / \mathrm{mm}$.

Fig. 4 shows the variation of Tangential Grinding Force per unit width per unit width with the Grinding depth for different wheel diameters $(125 \mathrm{~mm}, 200 \mathrm{~mm}$ and $250 \mathrm{~mm}$ ) at workpiece velocity, $\mathrm{V}_{\mathrm{w}}=0.3 \mathrm{~m} / \mathrm{s}$. The 
Figure reveals that there is no significant variation in the Tangential Grinding Force when the diameter of the wheel is varied. The variation of Tangential Grinding Force per unit width per unit width with the Grinding depth for different Wheel velocity at Workpiece velocity, $\mathrm{V}_{\mathrm{w}}=0.03 \mathrm{~m} / \mathrm{s}$ is presented in Fig. 5, it shows that the Tangential Grinding Force decreases as the Grinding wheel velocity increases.

Fig. 6 shows the variation of Tangential Grinding Force per unit width with the Grinding depth for different workpiece velocity and different wheel diameter at wheel speed, $V_{s}=24 \mathrm{~m} / \mathrm{s}$. It can be inferred from Fig. 6 that the Tangential Grinding Force per unit width remains relatively constant for any value of wheel diameter while it increases with increase in workpiece feed velocity. The variation of Tangential Grinding Force per unit width with the Workpiece Feed Velocity for different wheel velocity at Grinding depth, $a_{p}=0.001 \mathrm{~mm}$ is shown in Fig. 7, the figure shows that the Tangential Grinding Force per unit width required for grinding the workpiece increases as the velocity of the workpiece feed increases. Fig. 8 shows the variation of Tangential Grinding Force model per unit width with the Workpiece Feed Velocity for different wheel velocity at Grinding depth, $\mathrm{a}_{\mathrm{p}}=0.005 \mathrm{~mm}$, Fig. 8 reveals that the Tangential Grinding Force per unit width required for grinding the workpiece increases as the velocity of the workpiece feed increases. Comparing Fig. 7 and Fig. 8, it can be inferred that the Tangential Grinding Force per unit width required for grinding depth of $0.005 \mathrm{~mm}$ is greater than that required for a grinding depth of $0.001 \mathrm{~mm}$.

The variations of Tangential Grinding Force per unit width with the Workpiece Feed Velocity for different wheel diameter at Grinding depths, $\mathrm{a}_{\mathrm{p}}=0.001 \mathrm{~mm}$ and $\mathrm{a}_{\mathrm{p}}=0.005 \mathrm{~mm}$ are presented in Fig. 9 and Fig. 10 respectively, The figures revealed that the Tangential Grinding Force per unit width increases with increase in workpiece feed velocity but remained relatively constant with the grinding wheel diameter.

The result of model for Variation of Tangential Grinding Force per unit width with the Grinding Wheel Velocity for different Grinding depth at Workpiece Feed Velocity, $V_{w}=0.15 \mathrm{~m} / \mathrm{s}$ and wheel diameter, $d_{e}=125 \mathrm{~mm}$ is shown in Fig. 11, the figure indicates that Grinding wheel velocity decreases in a non linear manner with increase in Tangential Grinding Force. Fig. 12 shows the model output for
Variation of Tangential Grinding Force per unit width with the Grinding Wheel Velocity for different Grinding depth at Workpiece Feed Velocity, $\mathrm{V}_{\mathrm{w}}=$ $0.3 \mathrm{~m} / \mathrm{s}$ and wheel diameter, $d_{\mathrm{e}}=125 \mathrm{~mm}$, Fig 12 also reveals that Grinding wheel velocity decreases with increase in Tangential Grinding Force. Fig. 11 and Fig. 12 revealed that as the grinding depth required for grinding workpiece increases, the corresponding tangential grinding force also increased. Comparison of Fig. 11 and Fig. 12 indicates that increase in Workpiece feed velocity leads to a corresponding increase in Tangential Grinding Force. The correlation coefficient $\mathrm{r}^{2}$ computed $(0.9583$ and 0.9285 for feed velocities of $0.15 \mathrm{~m} / \mathrm{s}$ and $3.0 \mathrm{~m} / \mathrm{s}$ respectively) showed that our model is in good agreement with experimental result (Yang et al., 2003).

Fig. 11 and Fig. 12 are similar to Fig. 13 and Fig 14 respectively except for the wheel diameter that was changed from $125 \mathrm{~mm}$ to $200 \mathrm{~mm}$. Figures $11-14$ suggested that Tangential Grinding Force does not vary significantly with variation in wheel diameter.

\subsection{Normal Grinding Force}

Fig. 15 is the model variation of Normal Grinding Force per unit width with the Grinding depth for different Workpiece Velocity at Wheel speed, $\mathrm{V}_{\mathrm{s}}$ $=24 \mathrm{~m} / \mathrm{s}$, it can be deduced form the figure that the grinding depth of a workpiece material increases with increase in the Normal Grinding Force per unit width. Fig. 15 also revealed that the workpiece feed velocity increases with increase in Normal Grinding Force. Fig 16 shows the model for the variation of Normal Grinding Force per unit width with the Grinding depth for different Wheel Velocity at Workpiece velocity, $\mathrm{V}_{\mathrm{s}}$ $=0.03 \mathrm{~m} / \mathrm{s}$, from this figure it can be inferred that the grinding depth is directly proportional to the Normal Grinding Force.

Model result for variation of Normal Grinding Force per unit width with the Grinding Wheel Velocity for different Grinding depth at Workpiece Feed Velocity, $\mathrm{V}_{\mathrm{w}}=0.15 \mathrm{~m} / \mathrm{s}$ and wheel diameter, $\mathrm{d}_{\mathrm{e}}=125 \mathrm{~mm}$ is shown in Fig. 17, which revealed that Normal Grinding Force increases with decrease in Grinding wheel velocity but increases with increase in grinding depth of the workpiece material. Fig. 18 is the model result for variation of Normal Grinding Force per unit width with the Grinding Wheel Velocity for different Grinding depth at Workpiece Feed Velocity, $\mathrm{V}_{\mathrm{w}}=$ $0.3 \mathrm{~m} / \mathrm{s}$ and wheel diameter, $\mathrm{d}_{\mathrm{e}}=125 \mathrm{~mm}$, Fig. 18 
inferred that the Normal Grinding Force increases with decrease in Grinding wheel velocity but increases with increase in grinding depth of the workpiece. Comparing Fig. 17 and Fig. 18, it can be seen that increase in workpiece feed velocity leads to a corresponding increase in Normal Grinding Force. With all the parameters in Fig. 17 and Fig. 18 the same except for the workpiece feed velocity, $\mathrm{V}_{\mathrm{w}}$ which were $0.15 \mathrm{~m} / \mathrm{s}$ and $0.3 \mathrm{~m} / \mathrm{s}$ respectively, the highest normal grinding force for the two cases were $9.07237 \mathrm{~N} / \mathrm{mm}$ and $19.58487 \mathrm{~N} / \mathrm{mm}$ respectively. This suggested that the Normal Grinding Force required for grinding a workpiece if the velocity of workpiece is increased from $0.15 \mathrm{~m} / \mathrm{s}$ to $0.3 \mathrm{~m} / \mathrm{s}$ will be $10.5125 \mathrm{~N} / \mathrm{mm}$.

Fig. 19 and Fig. 20 presents the model for variation of Normal Grinding Force per unit width with the Grinding Wheel Velocity for different Workpiece Feed Velocity at and wheel diameter, $\mathrm{d}_{\mathrm{e}}=125 \mathrm{~mm}$ and Grinding depth, $a_{p}=0.001 \mathrm{~mm}$ and $a_{p}=0.005 \mathrm{~mm}$ respectively, Fig. 19 and Fig. 20 revealed that Grinding wheel velocity decreases as the Normal Grinding Force increases, however, Normal Grinding Force increases with increase in grinding depth. Fig. 21 and Fig. 22 show the result of the model for the variation of Normal Grinding Force per unit width with Workpiece Feed Velocity for different the Grinding Wheel Velocity at wheel diameter, $\mathrm{d}_{\mathrm{e}}=125 \mathrm{~mm}$ and Grinding depth, $\mathrm{a}_{\mathrm{p}}=0.001 \mathrm{~mm}$ and $\mathrm{a}_{\mathrm{p}}=0.005 \mathrm{~mm}$ respectively, the figures revealed that increase in velocity of the workpiece leads to increase in Normal Grinding Force. Comparing Fig. 21 and Fig. 22 showed that Normal Grinding Force is higher for grinding depth of $0.005 \mathrm{~mm}$ than the grinding depth of $0.001 \mathrm{~mm}$ indicating that as the grinding depth required increases, the corresponding Normal Grinding Force required also increased.

\subsection{Correlation between Tangential and Normal Grinding Forces}

Fig. 23 shows the Relationship between Normal Grinding Force per unit width and Tangential Grinding Force per unit width with Workpiece Feed Velocity at Grinding depth, $a_{p}=0.001 \mathrm{~mm}$. Fig. 23 indicates that at lower workpiece feed velocity $(11 \mathrm{~m} / \mathrm{s})$, the Normal Grinding Forces is fairly higher than the Tangential Grinding Force but as the workpiece feed velocity increases the difference between Normal and Tangential Grinding Forces decreases till $14 \mathrm{~m} / \mathrm{s}$ workpiece feed velocity when Normal and Tangential Grinding Forces assume the same value. From 15m/s upward, the value of Normal and Tangential Grinding Forces diverges out with Tangential Grinding Force having a higher value. Fig. 24 shows the relationship between Normal Grinding Force per unit width and Tangential Grinding Force per unit width with Workpiece Feed Velocity at Grinding depth, $a_{p}=$ $0.005 \mathrm{~mm}$, Fig. 24 shows that Normal Grinding Force is higher than the Tangential Grinding Force. Table 4.1 shows the model result and experimental result of Yang, et al.[19] for Tangential Grinding Force at various values of Grinding Depth, the results shows that the model result is well correlated with the experimental value.

Table: 4.1: Tangential Grinding Force for various values of Grinding Depth, Model result and experimental result

\begin{tabular}{|c|c|c|c|c|}
\hline \multirow{4}{*}{$\begin{array}{l}\text { Grinding } \\
\text { Depth, } a_{p} \\
\text { (mm) }\end{array}$} & \multicolumn{4}{|c|}{ Grinding wheel velocity, $\mathrm{V}_{\mathrm{s}}=24 \mathrm{~m} / \mathrm{s}$} \\
\hline & \multicolumn{2}{|c|}{$\begin{array}{l}\text { Workpiece Feed Velocity, } \\
\mathrm{V}_{\mathrm{w}}=0.15 \mathrm{~m} / \mathrm{s}\end{array}$} & \multicolumn{2}{|c|}{$\begin{array}{c}\text { Workpiece Feed Velocity, } \\
\mathrm{V}_{\mathrm{w}}=0.3 \mathrm{~m} / \mathrm{s} \\
\end{array}$} \\
\hline & This work & $\begin{array}{l}\text { Experimental Result } \\
{[19]}\end{array}$ & This work & $\begin{array}{c}\text { Experimental Result } \\
{[19]}\end{array}$ \\
\hline & $\begin{array}{l}\text { Tangential Grinding } \\
\text { Force }(\mathrm{N} / \mathrm{mm}) \\
\end{array}$ & $\begin{array}{l}\text { Tangential Grinding } \\
\text { Force }(\mathrm{N} / \mathrm{mm})\end{array}$ & $\begin{array}{l}\text { Tangential Grinding } \\
\text { Force }(\mathrm{N} / \mathrm{mm})\end{array}$ & $\begin{array}{l}\text { Tangential Grinding } \\
\text { Force }(\mathrm{N} / \mathrm{mm})\end{array}$ \\
\hline 0.001 & 0.44547 & 0.554 & 0.7891 & 0.901 \\
\hline 0.002 & 0.72197 & 0.643 & 1.37855 & 1.266 \\
\hline 0.003 & 0.98496 & 0.911 & 1.96374 & 1.61 \\
\hline 0.004 & 1.039 & 1.039 & 2.5534 & 1.829 \\
\hline 0.005 & 1.188 & 1.188 & 3.14936 & 2.083 \\
\hline 0.006 & 1.363 & 1.363 & 3.75192 & 2.047 \\
\hline
\end{tabular}




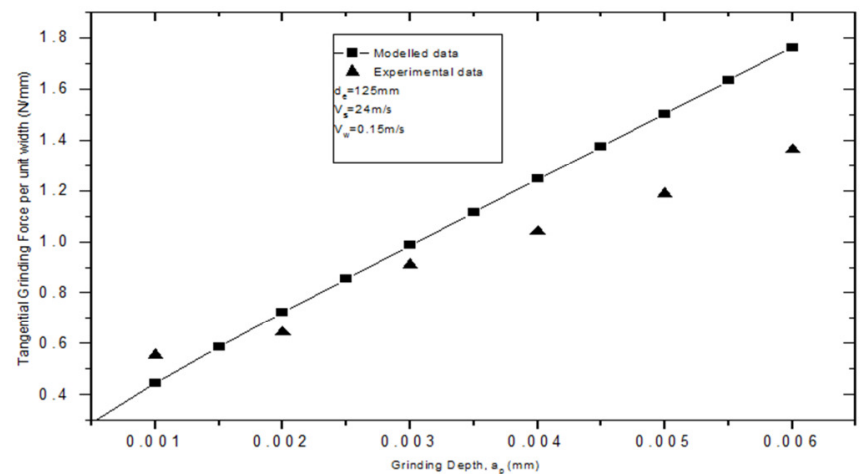

Fig. 1: Variation of Tangential Grinding Force per unit width with the Grinding depth at wheel speed, $\mathrm{V}_{\mathrm{w}}=0.15 \mathrm{~m} / \mathrm{s}$. Triangular symbol correspond to the experimental data [19]

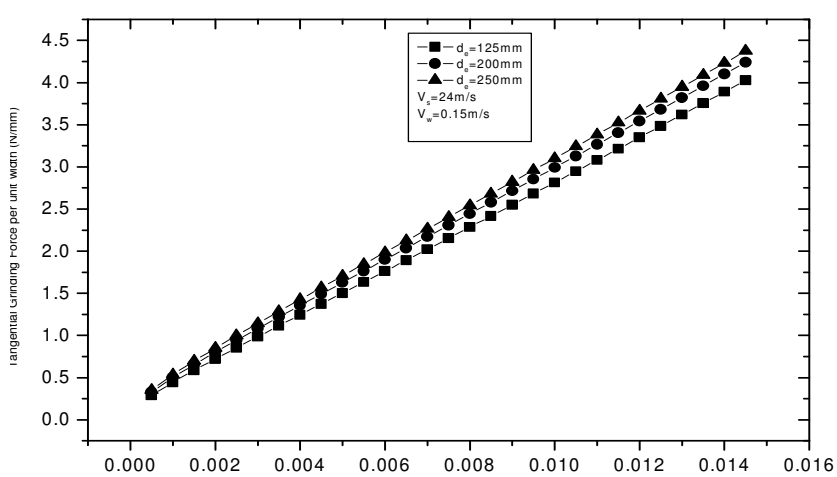

Fig. 2: Variation of Tangential Grinding Force per unit width per unit width with the Grinding depth for different wheel diameter at workpiece velocity, $V_{w}=0.15 \mathrm{~m} / \mathrm{s}$

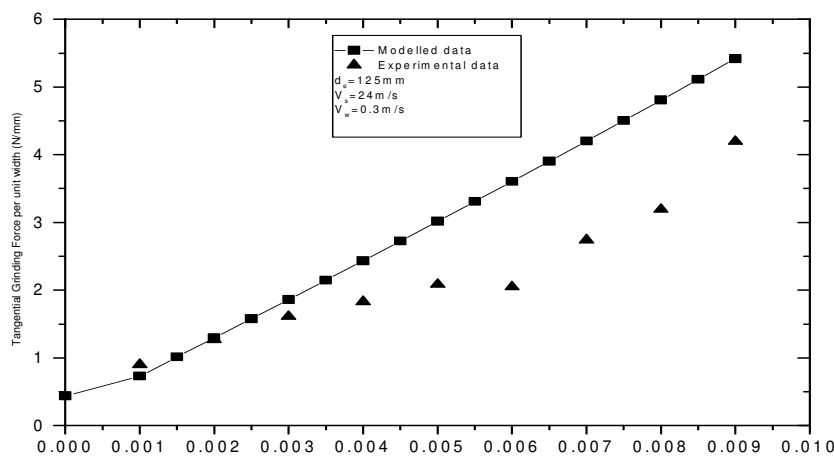

Fig. 3: Variation of Tangential Grinding Force per unit width per unit width with the Grinding depth at Workpiece velocity, $V_{w}=0.3 \mathrm{~m} / \mathrm{s}$. Triangular symbol correspond to the experimental data of [19]

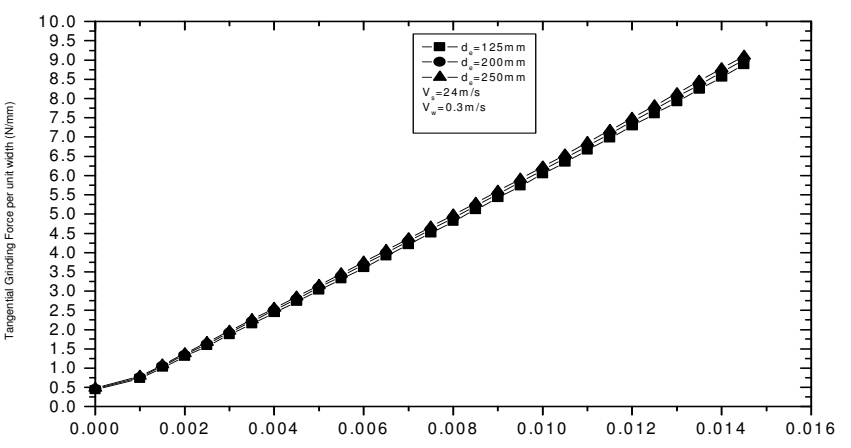

Fig. 4: Variation of Tangential Grinding Force per unit width per unit width with the Grinding depth for different wheel diameter at Workpiece velocity, $V_{w}=0.3 \mathrm{~m} / \mathrm{s}$

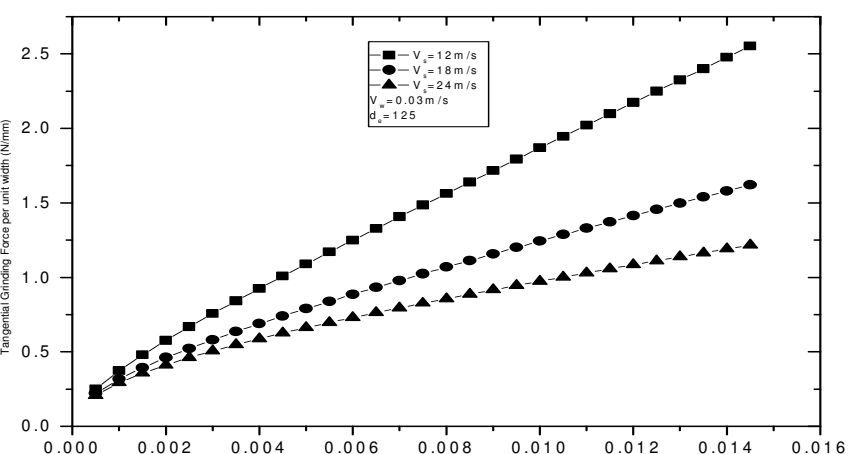

Fig. 5: Variation of Tangential Grinding Force per unit width per unit width with the Grinding depth for different Wheel velocity at Workpiece velocity, $V_{w}=0.03 \mathrm{~m} / \mathrm{s}$

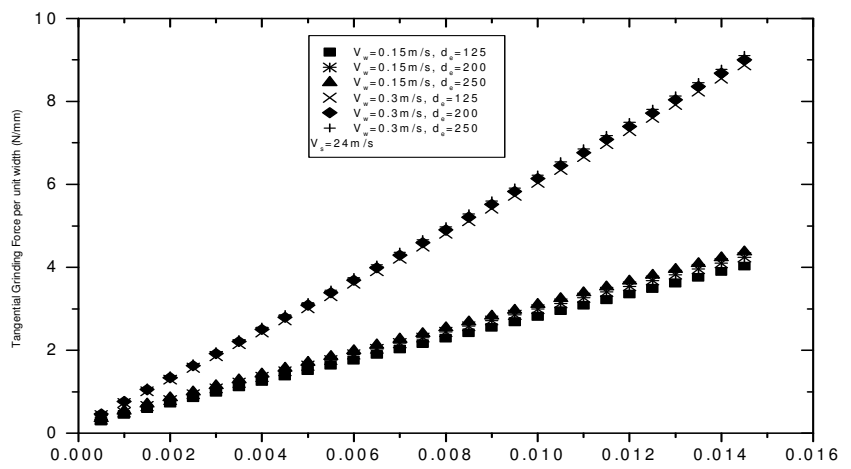

Fig. 6: Variation of Tangential Grinding Force per unit width with the Grinding depth for different workpiece velocity and different wheel diameter at wheel speed, $V_{s}=24 \mathrm{~m} / \mathrm{s}$

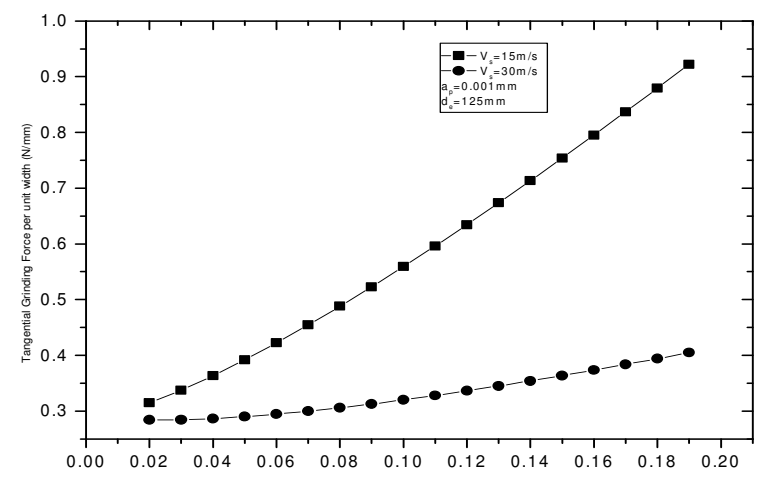

Fig. 7: Variation of Tangential Grinding Force per unit width with the Workpiece Feed Velocity for different wheel velocity at Grinding depth, $a_{p}=0.001 \mathrm{~mm}$

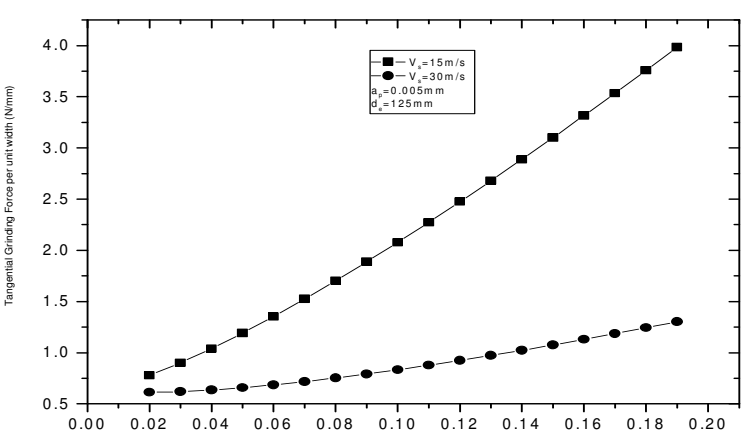

Fig. 8: Variation of Tangential Grinding Force per unit width with the Workpiece Feed Velocity for different wheel velocity at Grinding depth, $a_{p}=0.005 m$ 


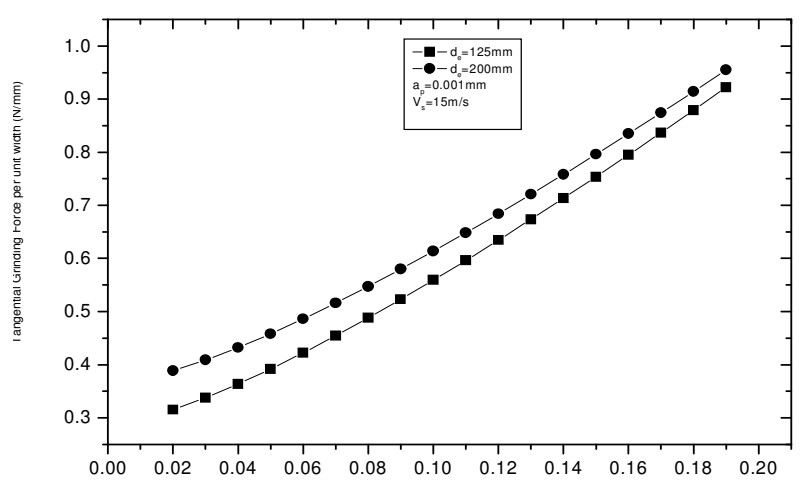

Fig. 9: Variation of Tangential Grinding Force per unit width wqewith the Workpiece Feed Velocity for different wheel diameter at Grinding depth, $a_{p}=0.001 \mathrm{~mm}$

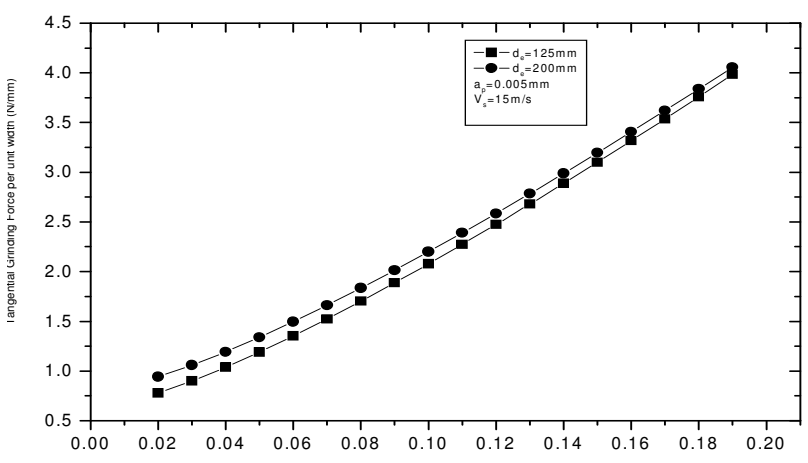

Fig. 10: Variation of Tangential Grinding Force per unit width with the Workpiece Feed Velocity for different wheel diameter at Grinding depth, $a_{p}=0.005 \mathrm{~mm}$

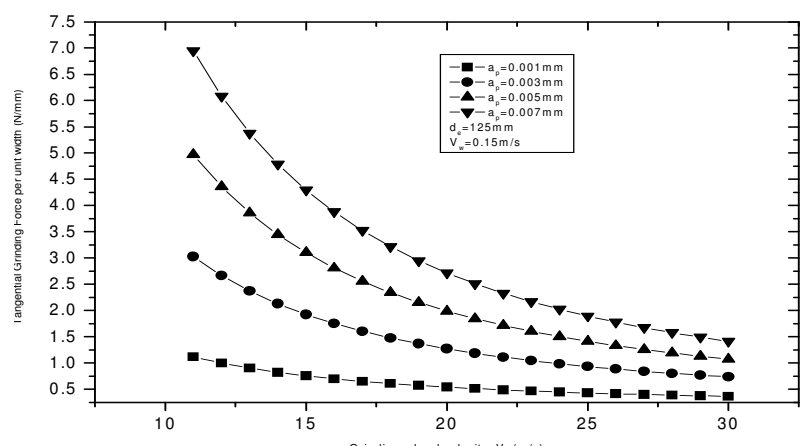

Fig. 11: Variation of Tangential Grinding Force per unit width with the Grinding Wheel Velocity for different Grinding depth at Workpiece Feed Velocity, $V_{w}=0.15 \mathrm{~m} / \mathrm{s}$ and wheel diameter, $d_{e}=$ $125 \mathrm{~mm}$

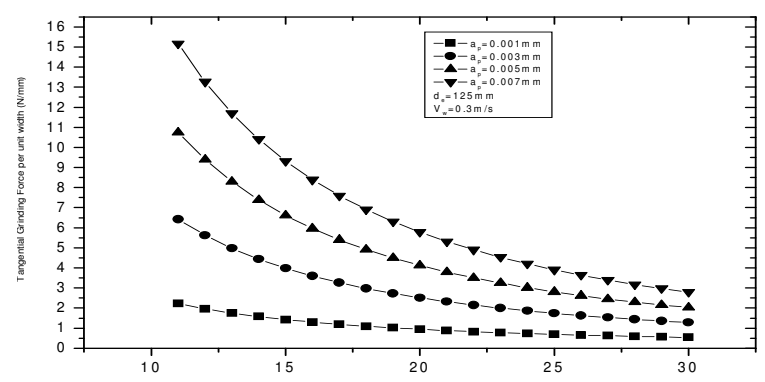

Fig. 12: Variation of Tangential Grinding Force per unit width with the Grinding Wheel Velocity for different Grinding depth at Workpiece Feed Velocity, $V_{w}=0.3 \mathrm{~m} / \mathrm{s}$ and wheel diameter, $d_{e}=$ $125 \mathrm{~mm}$

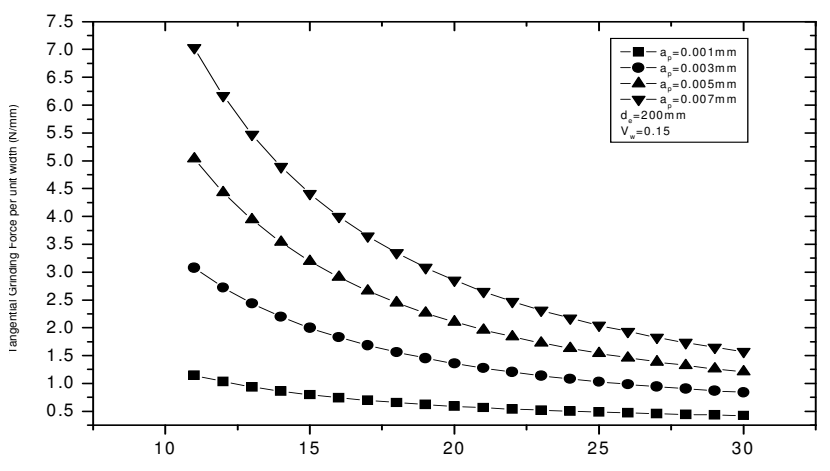

Fig. 13: Variation of Tangential Grinding Force per unit width with the Grinding Wheel Velocity for different Grinding depth at

Workpiece Feed Velocity, $V_{w}=0.15 \mathrm{~m} / \mathrm{s}$ and wheel diameter, $d_{e}=$ $200 \mathrm{~mm}$

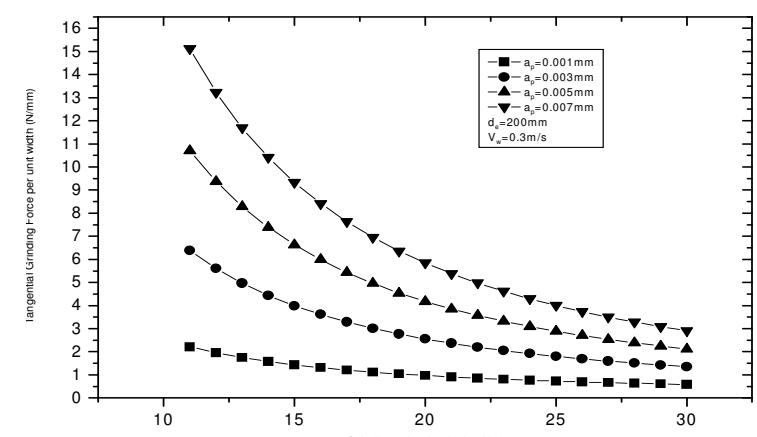

Fig. 14: Variation of Tangential Grinding Force per unit width with the Grinding Wheel Velocity for different Grinding depth at Workpiece Feed Velocity, $V_{w}=0.3 \mathrm{~m} / \mathrm{s}$ and wheel diameter, $d_{e}=$ $200 \mathrm{~mm}$

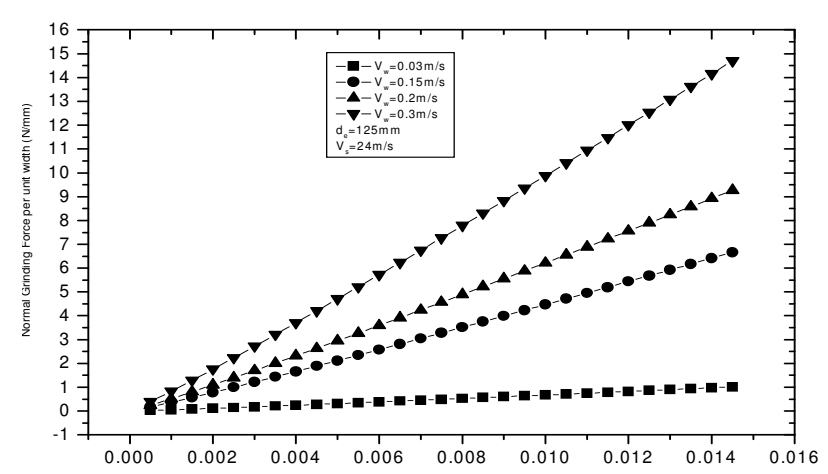

Fig. 15: Variation of Normal Grinding Force per unit width with the Grinding depth for different Workpiece Velocity at Wheel speed, $V_{s}$ $=24 \mathrm{~m} / \mathrm{s}$

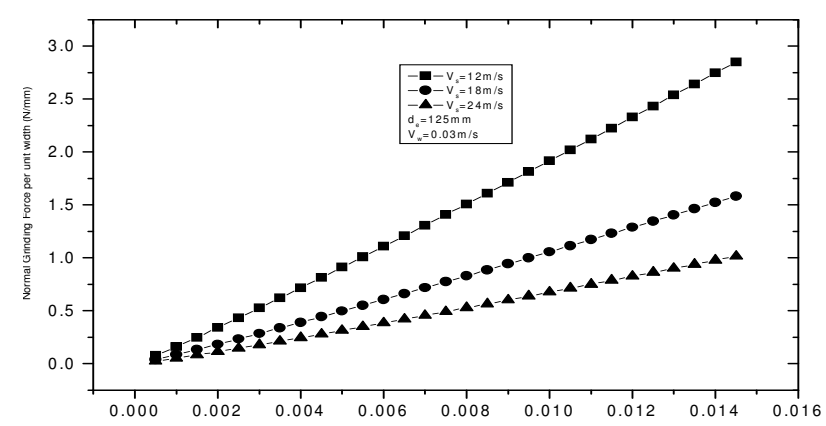

Fig. 16: Variation of Normal Grinding Force per unit width with the Grinding depth for different Wheel Velocity at Workpiece velocity, $V_{s}$ $=0.03 \mathrm{~m} / \mathrm{s}$ 


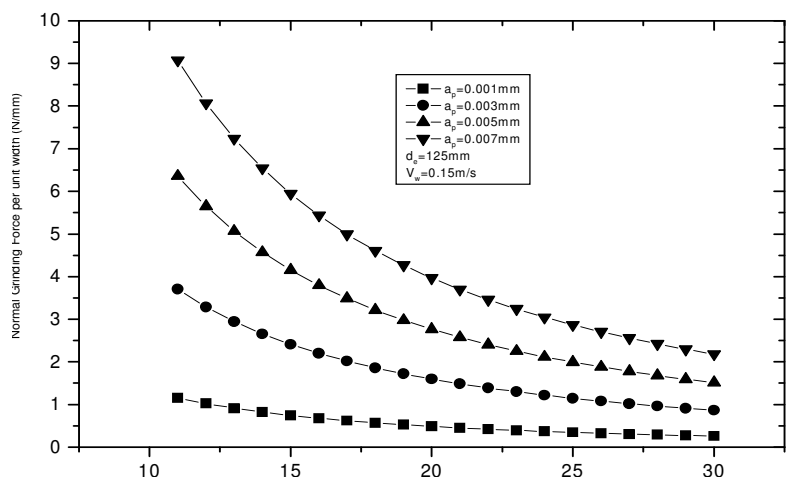

Fig. 17: Variation of Normal Grinding Force per unit width with the Grinding Wheel Velocity for different Grinding depth at Workpiece Feed Velocity, $V_{w}=0.15 \mathrm{~m} / \mathrm{s}$ and wheel diameter, $d_{e}=125 \mathrm{~mm}$

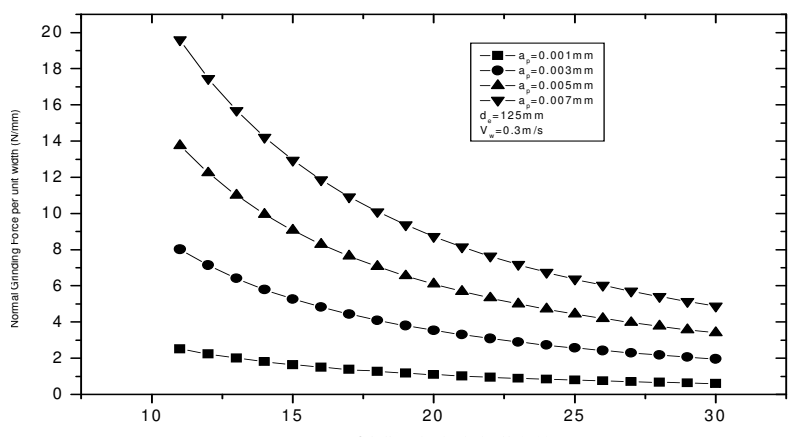

Fig. 18: Variation of Normal Grinding Force per unit width with the Grinding Wheel Velocity for different Grinding depth at Workpiece Feed Velocity, $V_{w}=0.3 \mathrm{~m} / \mathrm{s}$ and wheel diameter, $d_{e}=125 \mathrm{~mm}$

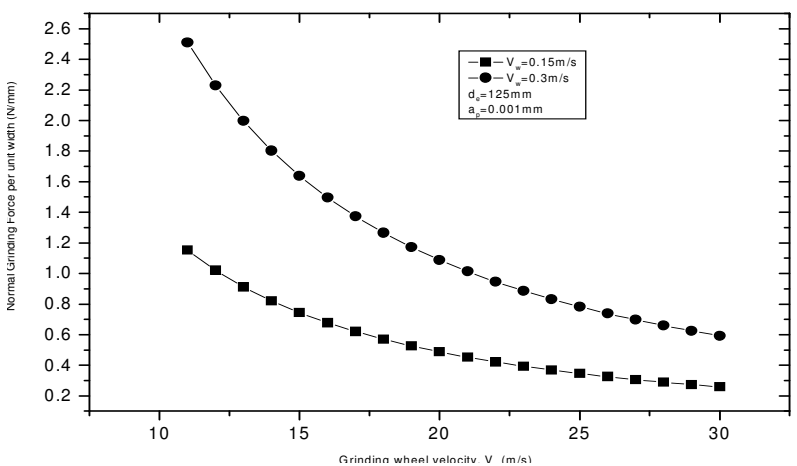

Fig. 19: Variation of Normal Grinding Force per unit width with the Grinding Wheel Velocity for different Workpiece Feed Velocity at Grinding depth, $a_{p}=0.001 \mathrm{~mm}$ and wheel diameter, $d_{e}=125 \mathrm{~mm}$

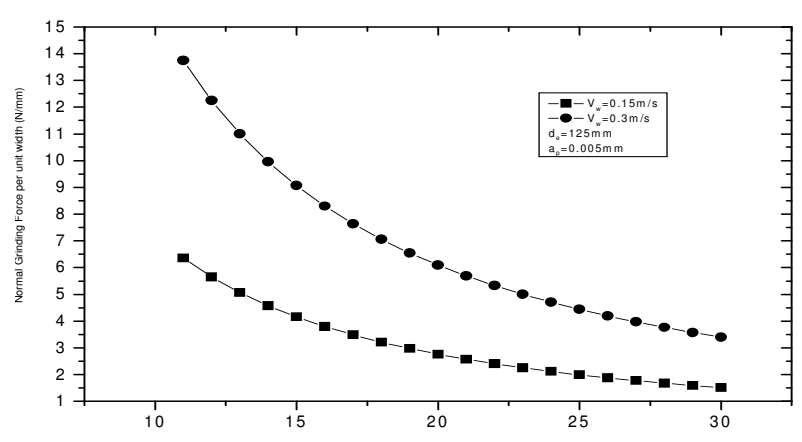

Fig. 20: Variation of Normal Grinding Force per unit width with the Grinding Wheel Velocity for different Workpiece Feed Velocity at Grinding depth, $a_{p}=0.005 \mathrm{~mm}$ and wheel diameter, $d_{e}=125 \mathrm{~mm}$

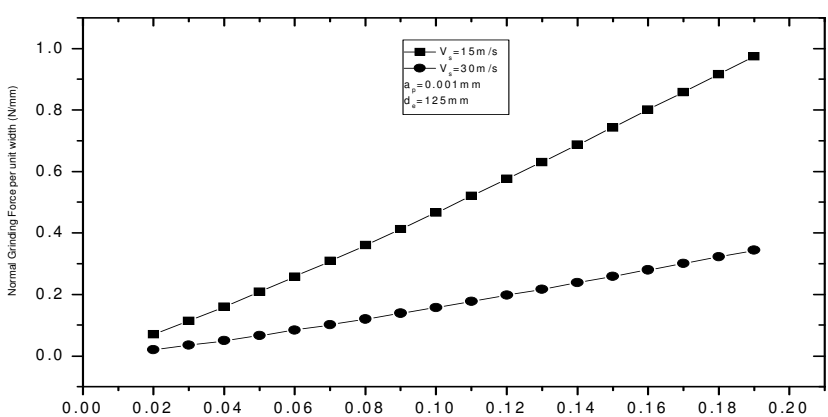

Fig. 21 Variation of Normal Grinding Force per unit width with Workpiece Feed Velocity for different the Grinding Wheel Velocity at Grinding depth, $a_{p}=0.001 \mathrm{~mm}$ and wheel diameter, $d_{e}=125 \mathrm{~mm}$

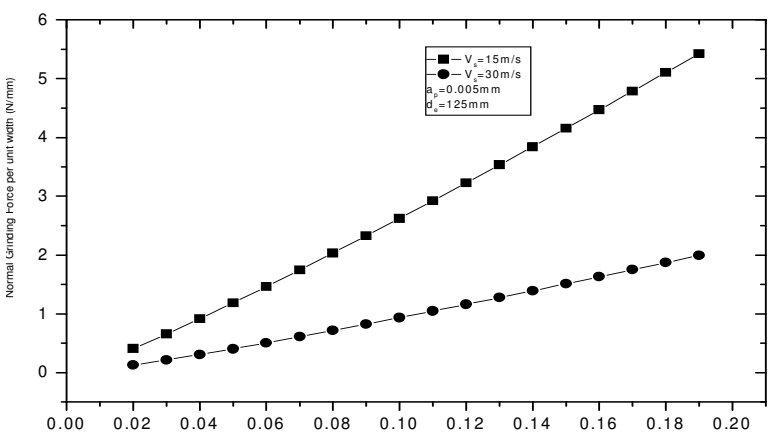

Fig. 22: Variation of Normal Grinding Force per unit width with Workpiece Feed Velocity for different the Grinding Wheel Velocity at Grinding depth, $a_{p}=0.005 \mathrm{~mm}$ and wheel diameter, $d_{e}=125 \mathrm{~mm}$

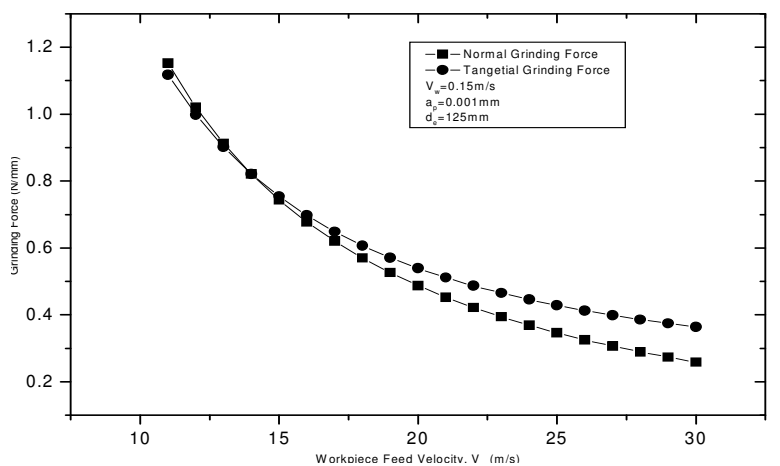

Fig. 23: Relationship between Normal Grinding Force per unit width and Tangential Grinding Force per unit width with Workpiece Feed Velocity at Grinding depth, $a_{p}=0.001 \mathrm{~mm}$

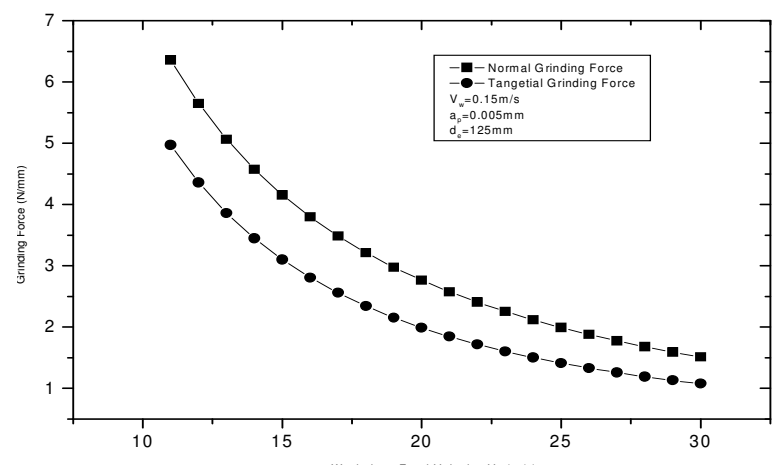

Fig. 24: Relationship between Normal Grinding Force per unit width and Tangential Grinding Force per unit width with Workpiece Feed Velocity at Grinding depth, $a_{p}=0.005 \mathrm{~mm}$ 


\section{CONCLUSION}

In this work, a model based computation for surface grinding process as micro-machining operation has been presented for Tangential and Normal Grinding Forces. The effect of workpiece feed velocity, grinding depth and grinding wheel velocity have been taken into account in this model. The model for grinding force takes into account the chip formation force and sliding force while the plowing force is not taken into account because it is relatively small compared to chip formation force. The model showed that the grinding forces (tangential and normal) are directly proportional to the grinding depth and workpiece feed velocity but are inversely proportional to the grinding wheel velocity. The model also revealed that the grinding wheel diameter does not significantly affect the Grinding forces.

\section{REFERENCES}

[1] Pereira, W. X., Diniz, A. E. and Hassui, A. “Comparing Different Plunge Cylindrical Grinding Cycles Based on Workpiece Roughness and Process Vibration" J. of the Braz. Soc. of Mech. Sci. \& Eng. ABCM, Vol. 31, Number 2, 2009, pp.161-166

[2] Aguiar, P. R., Catai, R. E., Bianchi, E. C. and Freitas, R. "Studies on the Cooling Minimum Quantity and Conventional Cooling at Hardened Steels in Grinding Process" J. of the Braz. Soc. of Mech. Sci. \& Eng., Vol. 29, Nunber2, 2007,pp136-141

[3] Malkin S. and Guo C. "Model Based Simulation of Grinding Processes; Department of Mechanical \& Industrial Engineering" University of Massachusetts, Amherst, USA, 2003.

[4] Anderson, D., Warkentin, A. and Bauer, R."Comparison of numerically and analytically predicted contact temperatures in shallow and deep dry grinding with infrared measurements" International Journal of Machine Tools \& Manufacture Vol.48, 2008,pp 320-328

[5] Amin, S. G., Ahmed, M. H. M., and Youssef, H. A."Computer-aided design of acoustic horns for ultrasonic machining using finite-element analysis" Journal of Material Processing Technology, Vol. 55, 1995, pp 254-260.

[6] Akbari, J., Borzoie, H., and Mamduhi, M. H."Study on Ultrasonic Vibration Effects on Grinding Process of Alumina Ceramic (Al203)" Proceedings of World Academy of Science, Engineering and Technology Vol. 31, 2008, pp. 2070-3740
[7] Walsh1, A.P., Baliga, B. and Hodgson, P.D. "Cycle Time Reduction in Crankshaft Pin Grinding" Abrasives Magazine, February/March 2002, pp. 26-30

[8] Walsh1, A.P., Baliga, B. and Hodgson, P.D. "Force modelling of the crankshaft pin grinding process" Proc. Instn Mech. Engrs Vol. 218 Part D: J. Automobile Engineering, 2003, pp. 219-227

[9] Chang, H.C. and Wang, J.J. "A stochastic grinding force model considering random grit distribution" International Journal of Machine Tools \& Manufacture, Vol. 48,2008,pp 1335- 1344

[10] Gavrilov, D., Vinogradov, O. and Shaw, W.J.D. "Simulation of Grinding in a shaker ball mill" J. Powder Technology, Vol. 101, 1999,pp 63-72.

[11] Shaw, W.J.D., Pan, J., and Gowler, M.A. "Property relationships of some new MA polymers" Proceedings of the $2^{\text {nd }}$ International Conference on Structural Applications of Mechanically Alloying, Vancouver, B.C., Canada, 1993, pp 431-437

[12] Stepien, P. "A probabilistic model of the grinding process" Applied Mathematical Modelling Vol. 33 2009, pp 3863-3884

[13] Ilio, A.D., Paoletti, A. and Addona, D.D. "characterization and modeling of the grinding process of metal matrix composites" CIRP Annals Manufacturing Technology, Vol. 58, 2009, pp. 291294

[14] Malekian, M., Park, S.S. and Jim, M.B.G. "Modeling of dynamic micro-milling cutting forces" Int. J. of Machine Tools and Manufacturing. Vol. 49, 2009, pp 586-598.

[15] Malkin, S. "Grinding Technology: Theory and Application of Machining with Abrasives, Ellis Horwood Ltd., Chichester, and John Wiley \& Sons, New York, 1989. pp. 76-88.

[16] Tang, J., Du, J. and Chen, Y "Modeling and experimental study of grinding forces in surface grinding" Journal of materials processing technology. Vol. 209, 2009, pp 2847-2854

[17] Kannappan, S. and Malkin, S. "Effect of Grain Size and Operating Parameters on the Mechanics of Grinding" Journal of Engineering for Industry. Vol. 94, 1972, pp. 833-842.

[18] Malkin, S., and Cook, N.H. "The wear of grinding wheels, part 1, attritious Wear" Journal of Engineering for Industry. Series B Vol. 93, 1971, pp 1120-1133.

[19] Yang, H., Sun, Y. and Cheng, Y. "Size effect in grinding" J. of Abrasive and Grinding Vol. 6, Number 78, 1993, pp 17-20. 